\title{
Experimental Evaluation of Cold Forging Lubricants Using Double-Cup-Extrusion-Tests
}

\author{
Robby Lorenz ${ }^{1, a^{*}}$, Hinnerk Hagenah ${ }^{1, b}$ and Marion Merklein ${ }^{1, c}$ \\ ${ }^{1}$ Friedrich-Alexander-Universität Erlangen-Nürnberg, Institute of Manufacturing Technology, \\ Erlangen, Germany \\ arobby.lorenz@fau.de, ${ }^{b}$ hinnerk.hagenah@fau.de, ${ }^{c}$ marion.merklein@fau.de
}

Keywords: Cold forming, Gear, Lubrication, Steel, Tribology

\begin{abstract}
Cold forging processes enable the economical production of high quality components like joints, shafts and gears. The manufactured parts are characterized by improved properties such as hardness, surface quality and fatigue strength. For manufacturing components using cold forging, a comprehensive knowledge regarding the cold forging procedure and its process parameters is needed. One important influencing factor, which needs to be analyzed to use the potential of this kind of processes, is the tribological system, especially the used lubricant. The tribological conditions significantly influence the material flow and thus the workpiece quality. Furthermore, resource efficient and environmentally benign metal forming processes became very important within the last decade. The present study evaluates the resulting tribological conditions and their differences for various cold forging lubricants with and without a zinc phosphate based lubricant carrier. The lubricants are based on molybdenum disulphide, polymers, or both inorganic salts and waxes. The tribological conditions of the different lubricants are investigated using the DoubleCup-Extrusion-Test (DCET) as a laboratory friction test.
\end{abstract}

\section{Introduction}

High quality components like joints, shafts and spur gears can be produced using different manufacturing technologies. The production of spur gears in particular is often done by machining due to the high reproducibility and the achievable geometrical accuracy, but spur gears can also be manufactured by metal forming processes like cold forging. Cold forged parts benefit from a wide range of technological and economic advantages. These advantages are for example excellent properties regarding hardness, resistance against deformation, continuous fibre orientation, strain hardening, residual compressive stresses, surface quality and fatigue strength [1]. Regarding economic aspects, cold forged parts benefit from high material utilisation and low cycle times. On the contrary, the attainable tolerance classes are better for machined spur gears. In cold forging operations, friction depends on the tribological system. This system consists of workpiece, tool, respective intermediate lubricant and environment. Considering the potentials and challenges for cold forging of spur gears listed above, the long-term objective while developing forward extrusion processes should focus on the improvement of the attainable tolerance classes. To realize this, a comprehensive knowledge regarding the frictional conditions and the lubricant behaviour in extrusion processes needs to be obtained, since the tribological conditions between workpiece and die can highly influence the attainable tolerance classes [2].

Since 1950, the need for more complex cold forging geometries in net shape has steadily risen. Since demanding cold forging processes can feature up to $3000 \%$ surface expansion, $2500 \mathrm{MPa}$ normal pressure, $200^{\circ} \mathrm{C}$ average tool and $600^{\circ} \mathrm{C}$ spike tool temperatures, appropriate lubricant systems were developed to meet the rising demands [3]. Particularly established in steel extrusion has been a zinc phosphate based pre-coating with chemical adhered sodium soaps due to its highly efficient lubrication properties. Primary, this conversion coating provides a much larger surface area for an improvement of the lubricant wetting on the steel billets. Secondly, chemical reactive lubricants, like soaps, can directly bond with the zinc phosphate coating, while chemical inert lubricants, like molybdenum disulphide or graphite, benefit from improved physical adhesion 
behaviour. [3] While being technologically superior, phosphate coatings involve numerous disadvantages, especially in consideration of environmental compatibility and resource efficiency. It produces a hazardous, heavy metal containing sludge, requires a lot of water, takes additional process time and needs to be applied at elevated temperatures. [4] To find suitable alternatives for conversion coating based lubricant systems, numerous research work has been conducted in the last decades to renounce from the zinc phosphate coating. The first remarkable single bath lubricant for this application, which does not need zinc phosphate coating, has been developed by Takeuchi et al. [5] in 1999 and was based on polymers, fatty acids, phosphates and $\mathrm{Zn}$ - and Mo-compounds. The investigations of Schoppe [6] resulted in the development of a lubricant system based on wax compounds, with inorganic salts acting as a bonding layer. Ghobrial et al. [7] evaluated amongst other lubricants a molybdenum disulfide based lubricant for cold forging operations with the help of the DCET. Nakamura et al. [8] conducted further research on lubricant alternatives based on metal soap and wax, as well as molybdenum disulfide and graphite. The lubricants were evaluated with a laboratory cold forging test with validation of the experiments in an industrial multistage cold extrusion process. Based on acrylic and methacrylic monomers, a co-polymeric environmentally friendly lubricant was developed by Ngaile et al. [9] and subsequently evaluated using Ring compression and Twist compression tests. Gariety et al. [10] used DCETs to compare the common soap-zinc phosphate lubricant system with polymer and inorganic salt based lubricants without zinc phosphate coating. Based on this literature review, three main lubricant bases for zinc phosphate free lubricant systems can be identified: molybdenum disulfides, polymers, and waxes combined with inorganic salts. One representative out of every main base was evaluated, in each case with and without zinc phosphate coating. This paper will focus on the investigation of the influence of different lubrication systems on the resulting friction factor with the DCET.

The principle of the DCET is the extrusion of two cups from a cylindrical test specimen. While the upper cup is formed by a backward extrusion process, the lower cup develops due to a forward extrusion process. During the forming process the lower punch remains stationary, while the upper punch forms the upper cup. The friction between die and workpiece significantly influences the resulting cup height ratio $R=h_{u} / h_{1}$, with $h_{u}$ and $h_{1}$ being the upper and lower cup heights, respectively. In order to be able to run the test correctly, there have to be identical tribological conditions between both the punches and the upper and lower surfaces of the specimen. Furthermore, both punches were designed with an undercut, to minimize the developed friction surface between billet and punches. No friction between die and billet leads to equal cup heights. With comparison to each other, high friction conditions will result in a higher upper cup height $h_{u}$ and a lower cup height $h_{1}$, see Fig. 1a. The state of adhesive friction is described by $m=1$, whereas a frictionless state is indicated by $m=0$. According to this, the parameters friction factor $m$ and cup height ratio $\mathrm{R}$ are directly proportional to each other. Thus, a low cup height ratio $\mathrm{R}$ indicates a low friction factor $\mathrm{m}$.

\section{Materials and Methods}

Experimental Setup. The set-up of the performed DCET is illustrated in Fig. 1b. The geometrical dimensions of both the cylindrical billet and the die were based on Andreas and Merklein [11]. The sensitivity of the DCET depends on the geometric ratio $h_{b} / d_{b}$ of the billet [12], with $h_{b}$ being the height and $d_{b}$ the diameter of the billet. This ratio was set to $\sim 1.5$, with $\mathrm{h}_{\mathrm{b}}=16.51 \pm 0.01 \mathrm{~mm}$ and $\mathrm{d}_{\mathrm{b}}=11.13 \pm 0.01 \mathrm{~mm}$. The inner diameter of the die $\mathrm{d}_{\mathrm{d}}$ is $11.20 \mathrm{~mm}$ and the surface of the tool steel was polished with a D6 diamond grit. By comparing the real measured cup height ratios from the experiments with the validated finite element model, the tribological conditions between billet and die can be determined using the principle of numerical identification. In order to obtain the calibration curve and to understand the influence of different friction factors $\mathrm{m}$ on the cup height ratio $\mathrm{R}$, the DCET was modeled by means of finite element analysis with the numerical software Simufact.forming.12.0.1. For the workpiece the Quadtree crosslinker with an element edge length of $0.2 \mathrm{~mm}$ was used, whereby two second stage refinement boxes were implicated between the contact surface of the workpiece and the punch. The validation of the 
experiment and the simulation model was done by validating the forming force $\mathrm{F}_{\mathrm{DCET}}$ and the relevant geometric dimensions of the extruded cups, see Fig. 1c.

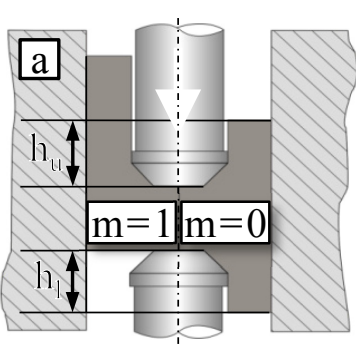

punch (G40) (X37CrMoV5-1)

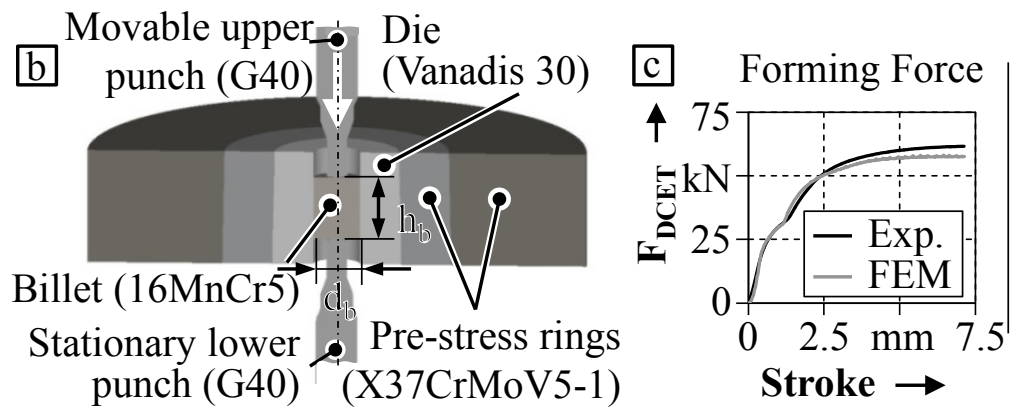

Stroke $\rightarrow$

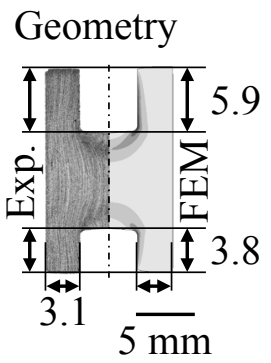

Fig. 1. DCET a) Principle and b) Test set-up, both amended accordingly [11]; c) Validation

Workpiece and Tool Material. The investigated workpiece material is a heat treatable steel $16 \mathrm{MnCr} 5$ (1.7131) with an initial yield stress of $503.97 \pm 1.40 \mathrm{MPa}$. It offers a high formability and machinability and is characterized by a high wear resistance. This steel is often used in the manufacturing of machine parts, transmissions components and gear parts. For the die the highspeed steel Vanadis $30(65.0 \pm 0.1 \mathrm{HRC})$ was chosen. The DCETs were conducted on the universal testing machine Schenk Trebel 400. The velocities of the upper traverse $v_{u t}$ and the stroke s were set to $5 \mathrm{~mm} / \mathrm{min}$ and $7.5 \mathrm{~mm}$, respectively.

Lubricant Systems. Three different lubricant bases were evaluated, see Table 1. Each of them was manually applied on both specimen types, with and without zinc phosphate coating, by dipping. Temperature, treatment time and dilution ratio were chosen in accordance to the recommendations of the manufacturer. The zinc phosphate coating was applied by Sachs from the ZF Friedrichshafen AG. All lubricants were diluted to a solid-state amount of $12.5 \mathrm{wt} . \%$ and applied in accordance with manufacturer information.

Table 1. Evaluated lubricants and general property characteristics of the main bases [13] [14]

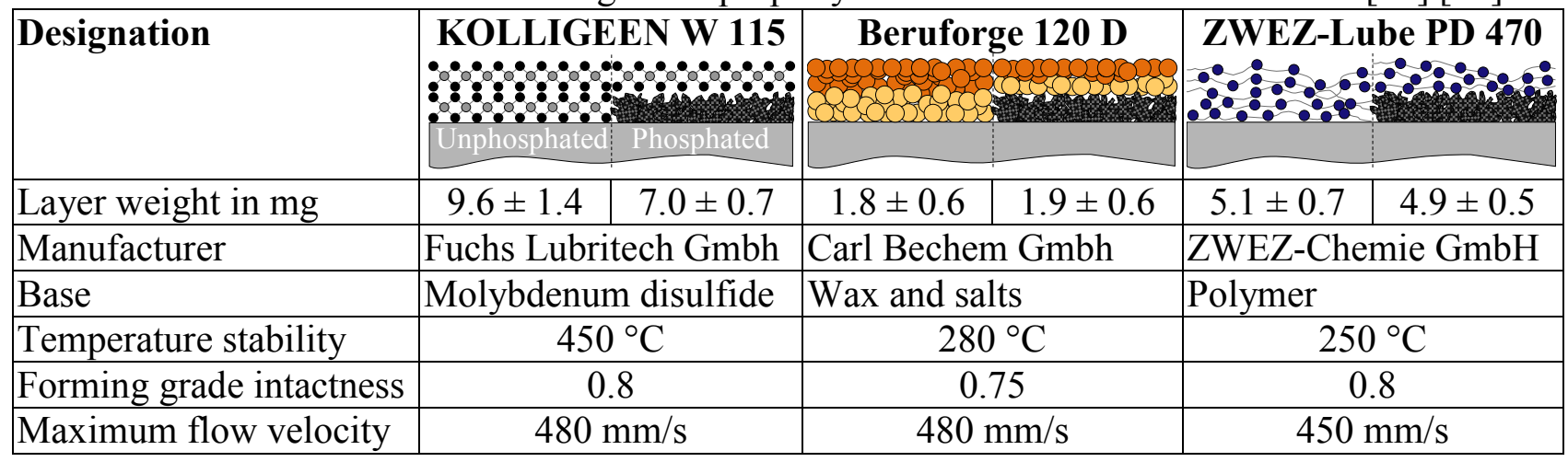

\section{Results and Discussion}

In order to ensure reproducibility of the results, $\mathrm{n}=14$ DCETs were performed and evaluated for each lubricant system, resulting in a total of $n=84$ DCETs. The distribution of the determined friction factors is shown in Fig. 2. Since the tribological conditions in the DCET are extremely sensitive for fluctuations in the experimental procedure, the median values $\tilde{\mathrm{m}}$ were chosen for evaluating the friction factors. The investigations carried out within the framework of these DCETs produced only one outlier. As it is shown in Fig. 2, all determined friction factors are below $\mathrm{m}=$ 0.1. This friction factor is often referred to as the standard value for cold forging operations in the literature [12]. Thus, all evaluated lubricants offer comparatively low frictional conditions between die and specimen. For each lubricant, the determined median friction factors for unphosphated billets were always comparably lower than the phosphated billets. The lowest friction factor median under the given conditions was determined for the wax based lubricant on unphosphated billets with $\mathrm{m} \approx 0.018$, whereas the highest friction factor median was measured for phosphated and molybdenum disulfide coated billets with $\mathrm{m} \approx 0.066$. For two of the three investigated lubricants, an 
observable effect on the scatter of the friction factors exists. There is also a visible effect of the phosphate layer by increasing the median in two of the three cases. As it can be seen in Fig. 2, applying a zinc phosphate coating not necessary yields lower friction factors. As a result, in no case a benefit of applying a phosphate layer can be seen in the friction factors. In case of the wax and polymer based lubricants the application of the phosphate coating resulted even in significantly higher friction factors than the application on the blank steel surface. A possible explanation for this contradictory behaviour could be the crystalline structure of the phosphate layer. If very coarse phosphate crystallites are produced on the specimen surface during the phosphating process, the forming process can lead to breaking and crushing effect of the phosphate crystallites, which again would have a negative effect on the frictional conditions between workpiece and die. The determined results for the friction factors are in accordance with the results of the studies by other authors, such as Wohletz et al. [15], who investigated similar lubricant systems using the sliding compression test. Sliding speed and sliding distance were investigated as significant factors influencing the lubricants performance. In order to justify the resulting friction factors, layer weight, lubricant concentration and surface roughness were analyzed in more detail. Gariety et al. [10] evaluated three different zinc phosphate free lubrication systems in comparison to the standard zinc phosphate coating and soap lubrication system by performing DCETs. In doing so, comparable or even lower friction factors for all three zinc phosphate-free lubricant systems were measured.

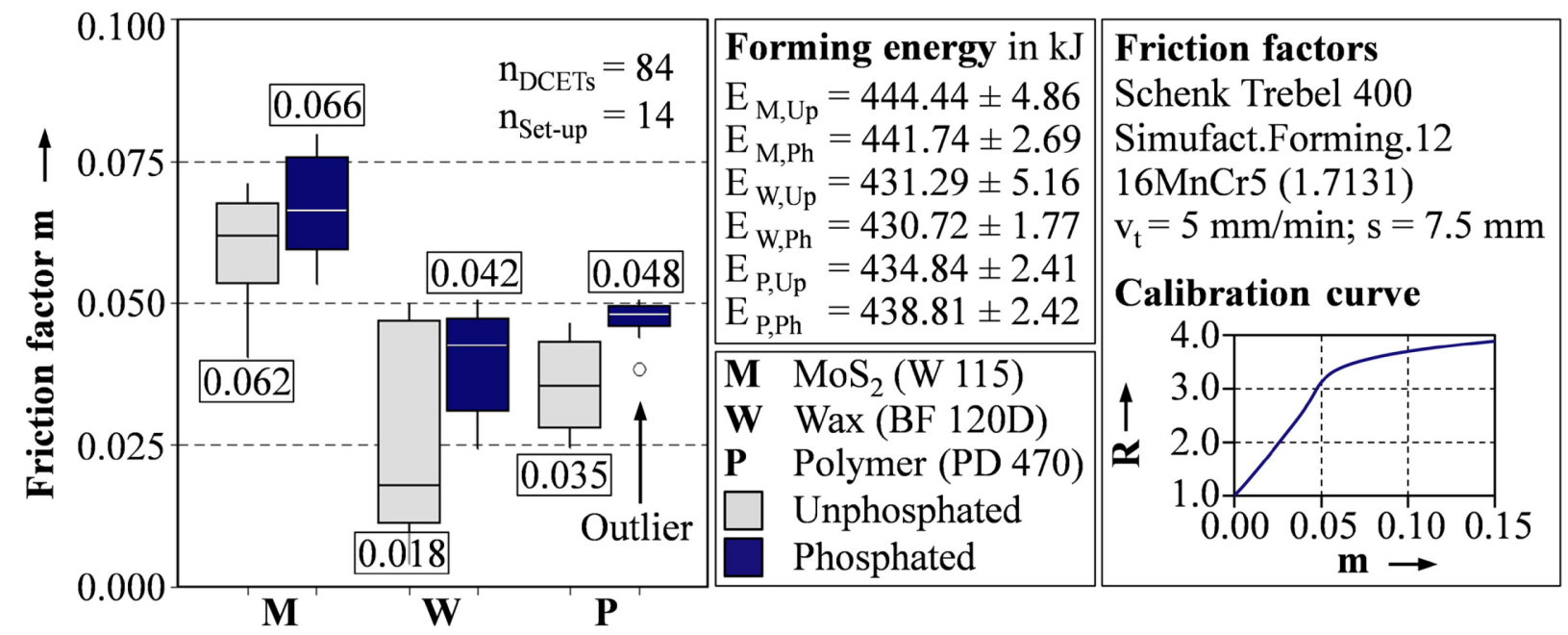

Fig. 2. Friction factor distribution of the DCETs illustrated by boxplot including forming energy

For the molybdenum based lubricant KOLLIGEEN W 115 a remarkable difference between unphosphated and phosphated experiments cannot be observed, the median values are almost similar. Since the course of the averaged force-displacement curves show only marginal differences and the utilization of only the maximum values of the forming force $F_{D C E T}$ can lead to false conclusions, the absolute forming energies $\mathrm{E}_{\mathrm{DCET}}$, which were calculated by the area underneath the curve, are given in Fig. 2. These calculated values $\mathrm{E}_{\mathrm{DCET}}$ correlate directly proportional with the determined frictional conditions between specimen and die. It is interesting to note that these comparatively high frictional values and forming forces are in accordance with Bay [3]. He states that $\mathrm{MoS}_{2}$ is often used in industrial applications due to its excellent lubricating, separating and emergency running properties, whereby higher forming and ejection forces can occur. This contradictory behaviour of $\mathrm{MoS}_{2}$ could be attributed to the unique lubrication mechanism of this lubricant, which is based on the gliding of the individual Mo-S-crystal layers to each other. The activation of the sliding process depends on the effective contact pressure between specimen and die, as well as the crystal plane directions against each other. These effects create an utterly complex and process-dependent lubrication property spectrum, which makes it difficult to identify the individual influencing factors precisely. Another important factor could be the overall wetting behavior and the resulting layer weight on the unphosphated and phosphated billets. Since the wetting behavior of the KOLLIGEEN W 115 was superior under both surface conditions, a proportional thick and rough layer was created on the surface of the billets. A possible explanation 
for this behaviour is the distribution of the lubrication particles on the specimen surface. In the case of the DCET the frictional state can vary between solid state friction and mixed friction. Latter can only be achieved if the lubrication film becomes completely enclosed between specimen and die, therefore creating a hydrostatic pressure-state. Only then, efficient lubrication and low friction can be ensured. If this is not the case, the lubricant becomes rather pushed out than lubricating and separating workpiece and die. Comparing the measured layer weight from Table 1 with the friction factors shown in Fig. 2, an indirect proportionality between layer weight and friction factor can be observed. This correlation is contradictory to the results of Wohletz et al. [15], although the DCET differs fundamentally from the compression test in terms of the tribological collective. In order to explain the lower friction factors of the wax and polymer-based lubricants, the surface roughness values average roughness $R_{z}$ and reduced peak height $R_{p k}$ of the specimen surfaces, which were measured by confocal microscopy with the VK-X 200, are shown in Table 2.

Table 2. Roughness values $\mathrm{R}_{\mathrm{z}}$ and $\mathrm{R}_{\mathrm{pk}}$ in $\mu \mathrm{m}$ before and after the DCETs

Phosphated

\begin{tabular}{|l|c|c|c|c|}
\hline & Before DCET & $\mathrm{MoS}_{2}(\mathrm{~W} 155)$ & Wax (BF 120D) & Polymer (PD 470) \\
\hline $\mathbf{R}_{\mathbf{z}}$ & $6.00 \pm 1.26$ & $5.94 \pm 1.07$ & $6.81 \pm 1.06$ & $7.64 \pm 1.41 \mu \mathrm{m}$ \\
\hline $\mathbf{R}_{\mathbf{p k}}$ & $0.97 \pm 0.23$ & $0.91 \pm 0.47$ & $1.02 \pm 0.63$ & $1.03 \pm 0.32 \mu \mathrm{m}$ \\
\hline \multicolumn{5}{|c|}{ Unphosphated } \\
\hline & Before DCET & $\mathrm{MoS}_{2}(\mathrm{~W} 155)$ & Wax (BF 120D) & Polymer (PD 470) \\
\hline $\mathbf{R}_{\mathbf{z}}$ & $4.61 \pm 0.37$ & $6.06 \pm 0.95$ & $5.44 \pm 0.54$ & $5.87 \pm 0.77 \mu \mathrm{m}$ \\
\hline $\mathbf{R}_{\mathbf{p k}}$ & $0.66 \pm 0.11$ & $0.67 \pm 0.17$ & $0.75 \pm 0.11$ & $0.82 \pm 0.14 \mu \mathrm{m}$ \\
\hline
\end{tabular}

\begin{tabular}{|ll|}
\hline \multicolumn{2}{|l|}{ Topography } \\
VK-X & 200 \\
$\lambda_{\mathrm{c}}$ & $0.8 \mathrm{~mm}$ \\
$\lambda_{\mathrm{s}}$ & $2.5 \mu \mathrm{m}$ \\
$1_{\mathrm{e}} / 1_{\mathrm{m}}$ & $0.8 / 4.0$ \\
$\mathrm{n}_{\text {Measure }}$ & 3 \\
$\mathrm{n}_{\text {Specimen }}$ & 5 \\
Measure- \\
ment
\end{tabular}

If a lubricant is able to create low frictional conditions between specimen and die, it offers good lubrication and separation properties. To quantify the latter, the corresponding $R_{p k}$ value can be used, since it describes the surface roughening and smoothing behaviour of the specimen, respectively. The $R_{p k}$ values which are depicted in Table 2 confirm this theory, as the $\mathrm{MoS}_{2}$ based lubricant resulted in both surface conditions in the smallest surface roughening. Contrary, all DCETs performed with wax and polymer lubricants resulted in higher roughness values $R_{p k}$, which can be explained by the formation of lubrication pockets, see Table 2. A direct comparison between phosphated and unphosphated conditions regarding the surface roughness would lead to false conclusions, since the initial unphosphated and phosphated structure was still observable after the execution of the DCETs. This is due to the forward and backward extrusion mechanism of the DCET, which is not able to create an observable amount of surface expansion. In summary, it was not possible to detect a major benefit from applying a phosphate layer. For environmental reasons its application should thus be omitted for these forging processes. While Beruforge $120 \mathrm{D}$ does yield the opportunity of reaching even lower friction factors it also results in much higher scatter. This puts additional challenges on process control and would result in a larger variety of the resulting workpieces, making closely tolerated, industrial productions more cumbersome. In conclusion, it is recommended to use ZWEZ-Lube PD 470 without a phosphate layer for cold forging processes that resemble tribological situations similar to the DCET, due to the possible low frictional factors and forming energies, as well as the high reproducibility of the measurements.

\section{Summary and Outlook}

Three lubricants on different bases, representing commonly applied lubricant categories, were evaluated regarding their frictional behavior by conducting DCETs. The influence of a phosphate layer on the resulting friction factor was also investigated. It was found that this coating resulted in no significant improvement for the lubrication properties of the investigated lubrication systems. The DCETs revealed that the molybdenum disulfide based lubricant resulted in both cases in the highest frictional conditions. However, the wax and polymer based lubricants caused much smaller friction losses. Since phosphate coating is an additional step in the cold forging manufacturing process chain, using polymer and wax based lubricants on unphosphated billets are both suitable 
single bath options for minimizing friction losses in cold forging processes and improving resource efficient forming processes. For best results under tribological conditions, which approximate those of the DCET, polymer based lubricants like the ZWEZ-Lube PD 470 are recommended. Further investigations should focus on the influence of the lubricant layer thickness and on analyzing the applicability of the investigated lubricants in the full-forward-extrusion process.

\section{Acknowledgement}

The authors would like to thank the German Research Foundation (DFG) for their financial support of the subproject TP-4, which is part of the DFG founded research unit 2271 "Processoriented tolerance management based on virtual computer-aided engineering tools".

\section{References}

[1] W. Niefer, Die Umformtechnik im Substitutionswettbewerb mit anderen Technologien, Tagungsband 3. Umformtechnisches Kolloquium Darmstadt (1988).

[2] F. Dohmann, N. Lüttel, Einfluß der Reibung auf die Qualität fließgepreßter Verzahnungen, Maschinenmarkt Würzburg 101 (1995) 20-23.

[3] N. Bay, The state of the art in cold forging lubrication, J. Mater. Process. Technol. 46 (1994) $19-40$.

[4] J. Donofrio, Zinc phosphating, Metal Finishing 108 (2010) 40-56.

[5] M. Takeuchi, N. Kashimura, F. Oda, Development of environmentally friendly lubricant with high performance and simple treatment for cold forging, J. JSTP 41 (2000) 109-114.

[6] J. Schoppe, Innovative cold massive forming on phosphate-free semi-finished products, Neuere Entwicklungen in der Massivumformung (2003) 305-312.

[7] M. I. Ghobrial, J. Y. Lee, T. Altan, N. Bay, B. G. Hansen, Factors affecting the double cup extrusion test for evaluation of friction in cold and warm forging, CIRP Ann. Manuf. Techn. 42 (1993) 347-351.

[8] T. Nakamura, Y. Sumioka, I. Ishibashi, M. Sekizawa, Lubrication performance of environmentally friendly lubricants for forging, Proc. Jap. Joint Conf. Techn. Past. (2008) 333-334.

[9] G. Ngaile, J. Cochran, D. Stark, Formulation of polymer-based lubricant for metal forming, Proc. Inst. Mech. Engi. Part B 221 (2007) 559-568.

[10]M. Gariety, G. Ngaile, T. Altan, Evaluation of new cold forging lubricants without zinc phosphate precoat, Int. J. Mach. Tool Manu. 47 (2007) 673-681.

[11]K. Andreas, M. Merklein, Influence of surface integrity on the tribological performance of cold forging tools, Procedia CIRP 13 (2014) 61-66.

[12]R. Geiger, Metal flow in combined cup extrusion, Reports Inst. for Form. Techn. 36 (1976).

[13]M. Kleinle, Etablierte Schmierstoffsysteme in der Kaltmassivumformung, 24. Jahrestreffen der Kaltmassivumformer (2009).

[14]S. Lenzer, Neue Tribo-Systeme für die Kaltumformung, 22. Jahrestreffen der Kaltmassivumformer (2007).

[15]S. Wohletz, C. Müller, S. Zang, P. Groche, Entwicklungen in der konversionsschichtfreien Kaltmassivumformung (2013) 120-131. 